\title{
SEKOLAH: \\ MEMBERDAYAKAN ATAU MEMPERDAYA MASYARAKAT
}

\author{
Hamka \\ STAIN Datokarama Palu, Jl. Diponegoro 23 Palu \\ e-mail: hamxaid@gmail.com
}

\section{Abstract}

Formal institution of education symbolized as "school" has been criticized by several experts since the last several decades. In one hand, this institution is judged to fail to do its tasks, both in forming the morality of the students and in transforming knowledge and skill needed by society. In other hand, this institution is judged as only a tool to legitimate class domination over inferior class. There are several solutions offered by experts, but the most realistic one is to do reformation in the side of the system of education focusing on the substance rather than on formality. And the very important thing to do is to change the paradigm of the society towards the school itself.

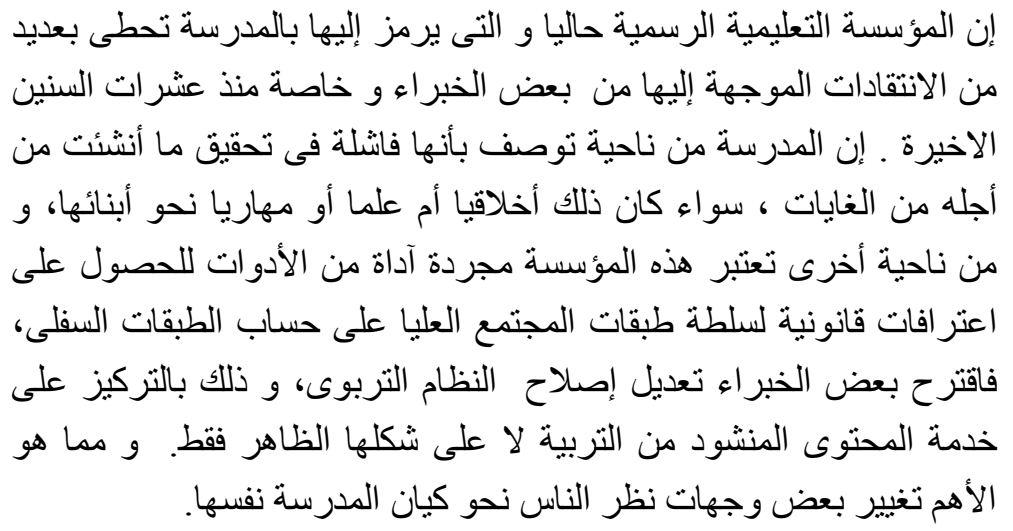

Kata Kunci: sekolah, pendidikan, kurikulum, masyarakat 


\section{PENDAHULUAN}

"Nenek ingin aku memperoleh pendidikan, karenanya dia melarangku sekolah", demikian ungkapan yang cukup populer dari Margaret Mead yang - antara lain — dimuat pada sampul buku Sekolah Kapitalisme yang Licik: Dialog Bareng Paulo Freire (Escobar dkk.. 1998). Pernyataan ini memberi kesan bahwa sekolah sebagai sebuah lembaga yang kontrakdiktif dengan nilai-nilai pendidikan. Sungguh sangat ironis, karena dalam pandangan umum, sekolah justru telah dinobatkan sebagai lembaga pendidikan formal yang paling terpercaya hingga hari ini.

Kita boleh-boleh saja tidak setuju dengan ungkapan di atas, tetapi paling tidak, kita tidak ikut-ikutan "mengkultuskan" lembaga persekolahan sebagai lembaga paling berkompeten dalam memanusiakan manusia. Pandangan seperti ini (pengkultusan sekolah) telah mengakar kuat di tengah-tengah masyarakat. Orang tua akan merasa sangat berdosa bila tak dapat menyekolahkan anaknya, karena merasa bahwa tanpa melalui lembaga ini masa depan anak akan terancam. Beberapa tahun yang lalu, seorang ibu rumah tangga di Jepang tega membunuh anaknya lalu kemudian bunuh diri, hanya karena sang anak tidak mau sekolah. Kekhawatiran sang ibu akan masa depan anaknya yang tidak mau sekolah itu membuatnya frustasi dan melakukan tindakan irrasional tersebut (Azra, 2000:164). Fakta ini menunjukkan bahwa sekolah benar-benar telah mampu membius kesadaran kolektif masyarakat untuk percaya bahwa "dialah" satusatunya jalan untuk mendidik manusia guna meraih kesuksesan di masa depan. Sekolah dengan demikian, menurut Roem Topatimasang (1998), telah menjadi candu masyarakat.

Artikel ini ingin mengajak pembaca untuk menengok keberadaan sekolah yang merupakan salah satu institusi paling berpengaruh di abad modern. Pemaparan ini akan diawali dengan sejumlah kritik yang dilontarkan oleh para pemerhati sekolah dalam menilai peran lembaga persekolahan di tengah masyarakat.

\section{APA YANG DILAKUKAN SEKOLAH}

Apa sebenarnya yang telah dilakukan oleh sekolah? Benarkah ia dapat mendidik moral? Lalu mengapa tawuran pelajar lebih sering terdengar dari pada tawuran anak jalanan (yang tidak bersekolah). 
Apakah sekolah telah berhasil mencetak tenaga kerja terampil? Lalu mengapa perusahaan masih perlu memberi training bagi para karyawannya sebelum mereka dipekerjakan? Dan bila sekolah dipandang sebagai tempat untuk mempersiapkan diri memasuki dunia kerja, apakah hasil kerja itu nantinya bisa setimpal dengan investasi usia (juga dana tentunya) yang telah dihabiskan untuk bersekolah, padahal waktu (umur) merupakan sumber daya yang tak pernah bisa didaur ulang.

Jika benar sekolah merupakan tempat belajar yang terpercaya, lalu mengapa kursus-kursus, dan bimbingan belajar masih marak, padahal materi yang dikaji sudah tertuang dalam kurikulum sekolah? Lalu, di mana sebenarnya fungsi sekolah?

Dalam pandangan Illich (1972), lembaga persekolahan pada dasarnya hanya sebuah lembaga yang berfungsi untuk memperkuat struktur kaum atas yang telah mapan, dan karena itu beliau menyarankan agar semua sistem kelembagaan pendidikan dihapuskan saja. Hal senada juga diungkap oleh Paulo Freire (1985:23) bahwa pendidikan dengan struktur institusionalnya hanya merupakan alat untuk menyebarluaskan penindasan terhadap rakyat kecil, penindasan melalui sistem pendidikan, sehingga rakyat kecil kehilangan kesadaran terhadap diri sendiri maupun kenyataan yang menindas itu. Rakyat miskin seakan harus pasrah menerima suratan takdir dan terkurung dalam suatu "kebudayaan bisu" (culture of silence). Reimer (2000:13-23) menyatakan bahwa bagi kebanyakan orang sekolah adalah pendukung previlese, bahkan di saat yang sama merupakan instrumen bersama bagi mobilitas vertikal masyarakat, apa yang dihasilkan dari sistem kelembagaan pendidikan semacam itu? Apakah betul-betul ada proses belajar, domokrasi dan kreativitas belajar yang sesungguhnya?

Kenyataan ini tergambar secara sempurna dalam fenomena keseharian kita. Lihatlah misalnya, Bimbingan Tes Masuk Perguruan Tinggi di mana si miskin akan menyerah sebelum berlaga. Anak-anak dari keluarga miskin nyaris tidak mendapatkan tempat di Perguruan Tinggi, khususnya Perguruan Tinggi yang berkualitas. Ketatnya persaingan memasuki dunia Perguruan Tinggi memaksa murid-murid SLTA memacu diri melalui Program Bimbingan Tes, dengan biaya yang tak terjangkau oleh mereka dari kalangan menengah ke bawah. 
Belum lagi mereka yang terpaksa berhenti di tengah jalan karena tak dapat menanggung biaya SPP yang kian melangit.

Pada akhirnya, hanya mereka dari kalangan atas yang memiliki kesempatan lebih besar untuk memegang "ijazah", dan ini tentu saja berimplikasi bagi kemapanan status sosial mereka dalam sebuah masyarakat yang sangat mengedepankan formalitas. Segeralah posisiposisi kunci dalam struktur sosial kemasyarakatan berada di bawah kendali mereka. Sekolah dengan demikian hanyalah instrumen dalam melegitimasi dominasi kelas atas terhadap kelas bawah. Dan kelas bawah secara tak sadar menerima hal itu sebagai sebuah hal yang wajar.

Kenyataan seperti itu membuktikan kebenaran teori konflik sosial dalam menilai lembaga pendidikan. Weber (dalam Collins 1974:420), misalnya, berpandangan bahwa sekolah dibentuk di bawah kekuasaan kelompok atau golongan yang dominan sesuai dengan tujuan mereka. Kepentingan kelompok merupakan landasan dalam menetapkan hal-hal ideal yang menentukan dalam sistem suatu sekolah. Sementara itu, Collins (1974:421), salah seorang pengikut teori sosiologi konflik neo-weberian, menyatakan bahwa aktivitas paling utama di sekolah bukanlah menanamkan pengetahuan teknis, tetapi bagaimana mengajarkan budaya status yang baik di dalam dan di luar kelas. Lembaga pendidikan berfungsi untuk memperkuat budaya status tersebut.

Kritikan terhadap sekolah bukan hanya sampai di situ. Sistem pembelajaran yang diterapkan di sekolah juga tidak luput dari kritikan para ahli. Freire (1985:49-70), misalnya, menyebut sistem pendidikan yang banyak diterapkan selama ini adalah pendidikan gaya "bank". Berbagai jenis mata pelajaran "ditabung" dalam benak anak didik, dan ketika diperlukan dapat ditarik keluar.

Sementara itu, Toffler (1992:356-358) menilai bahwa pendidikan massal merupakan mekanisme yang amat cerdik yang dikontruksi oleh industrialisme dalam memproduksi manusia yang mereka butuhkan. Sekolah telah menjadi mesin pendidikan, sejumlah besar pelajar dikumpulkan sebagai bahan baku, yang akan dikelolah oleh para pekerja (guru) dalam sebuah pabrik yang berlokasi sentral (sekolah). Mata pelajaran diorganisasikan dalam berbagai disiplin permanen berdasarkan asumsi industrial. Anak-anak berbaris dari satu 
tempat ke tempat yang lain, dan duduk ditempat yang telah ditunjuk, bel berdering untuk memberi tanda pergantian waktu, persis dalam dunia industri di mana bunyi peluit sebagai isyarat kapan para pekerja harus mulai bekerja, istirahat dan pulang. Dan yang paling memprihatinkan bahwa di sana tidak ada individualisasi, sistem yang kaku dalam pengaturan tempat duduk, pengelompokan, pembagian tingkat, pemberian nilai dan peran guru yang otoriter.

Dalam masyarakat modern saat ini, sekolah telah mengalami degradasi fungsional, dan semakin berorientasi materialistis. Akurasi suatu lembaga pendidikan diukur dari sejauh mana outputnya dapat berpartisipasi dalam dunia kerja. Sekolah ibarat pabrik yang siap mengolah bahan mentah (anak didik) menjadi bahan jadi yang siap pakai. Akibatnya, sekolah didikte oleh pasar tentang apa yang mesti mereka ajarkan kepada anak didik. Anak didik lalu disuguhi dengan sejumlah materi yang tidak ingin mereka ketahui, di sisi lain mereka tidak punya kesempatan untuk mempelajari apa yang ingin mereka ketahui. Lahirlah kemudian anak-anak yang suka bolos, atau bahkan tidak mau sekolah seperti yang telah dikemukakan. Beberapa tahun lalu diungkapkan bahwa sekitar 50.000 anak-anak di Jepang menderita sindrom yang oleh para ahli disebut sebagai "fobi sekolah". Sindrom ini berupa gejala dan tingkah laku yang mencerminkan rasa takut terhadap sekolah. Menurut para psikolog dan ahli pendidikan di Jepang, sindrom ini disebabkan oleh belenggu sistem pendidikan yang amat ketat di negara itu (Azra, 2000:164).

Menurut Azra (2000:163), salah satu bentuk paling menonjol dalam sistem pendidikan modern adalah sangat ketatnya birokrasi dan formalitas. Mekanisme semacam inilah yang mengatur dan mengarahkan orang-orang yang berada dalam lingkungan pendidikan. Pada akhirnya pemikiran dan tingkah laku yang muncul dalam proses pendidikan bukan lagi bersumber dari fitrah manusiawi, tetapi timbul dari birokrasi itu sendiri. Dan, lanjut beliau, tentu sulit mengharapkan lahirnya pribadi yang arif cendekia dari sistem pendidikan yang berlangsung dalam bentuk seperti ini.

Kungkungan formalitas dalam pembelajaran seperti yang tertuang dalam bentuk kurikulum yang amat kaku, justru merusak nilai pendidikan. Murid dituntut untuk "melahap" sejumlah materi pelajaran dalam batas waktu yang telah ditentukan, tanpa peduli 
apakah hal itu sesuai dengan tingkat perkembangan psikologis mereka. Dewey (1962a:7-10), menyoroti beberapa pertentangan yang tajam antara anak dengan kurikulum, yang paling mendasar adalah: pertama, jagat sempit personal anak versus jagat ruang dan waktu tanpa batas; kedua, kehidupan anak yang satu dan utuh versus spesialisasi dan pembagian dalam kurikulum; ketiga, ikatan-ikatan praktis-emosional dalam kehidupan anak versus prinsip abstrak tentang klasifikasi dan pengaturan logis.

Di sisi lain, lembaga persekolahan seringkali terjebak dalam rutinitas formal di balik pagar kurikulum yang kaku dan mengabaikan realitas sosial yang mengitarinya. Dewey (1962b:75) menegaskan bahwa suatu pemborosan besar yang dilakukan anak di sekolah, disebabkan oleh ketidakmampuannya menyatukan pengalamanpengalaman yang dilaluinya di luar sekolah dengan apa yang diterimanya di sekolah. Di samping itu, mereka juga tak mampu menerapkan apa yang mereka pelajari di sekolah ke dalam kehidupan sehari-hari. Sekolah terisolasi dari realitas kehidupan masyarakat dan lingkungannya. Hal ini terjadi bukan hanya pada tingkat dasar dan menengah, tetapi juga pada level Perguruan Tinggi. Pendidikan universitas, kata Freire (dalam Escobar, et. al., 1998:76) lazim melatih para mahasiswa membaca buku teks, kadang-kadang dengan efisien, namun buku-buku ini tidak benar-benar dibaca, karena ada dikotomi antara teks dan konteks. Dengan cara ini, universitas membaktikan tugas abstraknya dan muncul sebagai semacam kuil suci tempat purifikasi menjadi kebajikan.

Hal senada juga diungkapkan oleh Husen (1988:5) bahwa suatu penyakit profesional yang menjangkiti para pendidik di seluruh dunia, baik yang terjangkau oleh riset maupun yang tidak, adalah kebutaan terhadap kenyataan bahwa sekolah adalah dan haruslah merupakan bagian integral dari masyarakat sekitarnya, dan sama sekali tidak boleh bergerak di dalam kehampaan kehidupan sosial.

Ketika sekolah terisolasi dari realitas sosial yang mengitarinya, maka ia tidak mungkin dapat membawa perubahan apa pun dalam kehidupan sosial masyarakat. Dalam kondisi seperti ini lembaga persekolahan telah kehilangan fungsinya sebagai agent of social change, dan segera fungsi tersebut akan diambil alih oleh lembaga lain, khususnya dalam hal ini media massa. Karakter, perilaku, gaya 
hidup dan cara berfikir generasi muda kita, sama sekali tidak mencerminkan nilai-nilai yang diajarkan di sekolahan, melainkan refleksi yang sangat sempurna dari nilai-nilai yang ditanamkan oleh media massa.

\section{MASA DEPAN SEKOLAH DAN SEKOLAH MASA DEPAN}

Mungkinkah sekolah, dalam kondisinya seperti yang telah dipaparkan, dapat mempertahankan eksistensinya di masa yang akan datang? Jawabannya, sepanjang masyarakat masih meyakini ijazah sebagai jaminan hidup dan sepanjang sistem sosial kemasyarakatan kita masih mengedepan formalitas dari pada skill, maka sekolah akan tetap eksis bahkan mungkin secara kuantitas akan semakin bertambah banyak. Sekolah-sekolah elit akan bermunculan untuk memenuhi selera kalangan atas yang membutuhkan simbol bagi status sosial mereka. Sementara mereka dari kalangan menengah ke bawah akan melirik sekolah-sekolah yang dianggap manjur dalam memproduksi tenaga kerja praktis.

Namun, ketika sekolah tidak lagi mampu memenuhi harapan konsumennya, sekolah tidak lagi mencerminkan simbol prestise sosial, dan para alumnusnya satu persatu masuk dalam daftar pengangguran, maka sekolah pun segera memasuki masa sekaratnya. Bahkan bisa jadi kondisinya menjadi terbalik, sekolah menjadi momok sosial yang menakutkan, karena beban psikologis seorang alumnus sekolahan (sarjana) yang menganggur jauh lebih berat dari mereka yang tidak sekolah, dalam kondisi yang demikian, gelar akademik tak lagi menjadi kebanggaan tetapi menjadi aib sosial.

Singkatnya, kalau pun masih dapat bertahan, lembaga persekolahan di masa depan hadir dalam dua bentuk kepentingan yakni simbol gengsi dan pabrik tenaga kerja. Sedangkan fungsi kependidikannya akan punah, jika pendidikan diartikan, sebagaimana yang didefenisikan oleh Freire (dalam Reimer, 2000:111) sebagai proses yang secara kritis menyadarkan orang akan realitas dengan cara yang mengakibatkan tindakan efektif terhadap realitas itu. Seorang yang terdidik akan cukup memahami dunianya untuk dapat menanggulanginya secara efektif. Orang-orang semacam ini, kata Freire, kalau cukup jumlahnya tidak akan membiarkan adanya hal-hal yang tidak masuk akal di dunia yang sekarang. 
Hutchins (dalam Blackington, 1968:155-156), menegaskan bahwa fungsi utama lembaga pendidikan adalah mensuplai sarana, disiplin dan kerangka kerja intelektual yang diperlukan dalam memahami persoalan-persoalan baru yang akan kita hadapi. Oleh karena itu, manusia yang terdidik bukan sekedar manusia terlatih, tetapi manusia yang siap menghadapi kondisi apapun, senantiasa meningkatkan dan dapat memanfaatkan potensi dirinya, serta memahami segala persoalan baru yang akan dihadapinya. Ringkasnya, pendidikan yang dimilikinya membuatnya dapat belajar sepanjang masa .

Mungkinkah sekolah dapat melaksanakan tugas kependidikan semacam itu? Dalam pandangan Illich, tampaknya tidak mungkin, sehingga solusi yang beliau tawarkan adalah menghapuskan lembaga persekolahan itu sendiri. Hal yang sama juga disampaikan oleh Reimer, bahwa untuk meratakan pendidikan, maka kelembagaan seperti sekolah harus dilenyapkan karena ia telah kematian fungsi. Reimer justru menegaskan bahwa salah satu tugas terpenting kita adalah menyadarkan para orang tua dan majikan supaya memikul kembali tanggung jawab mereka di bidang pendidikan. Karena pendidikan yang sejati terjadi terutama di rumah dan di tempat kerja (Blackington, 1968:123).

Jika mengharapkan sekolah mampu melaksanakan tugas kependidikan dianggap sebagai sebuah utopia, mungkin lebih utopis lagi jika kita berpikir untuk menghapuskan lembaga yang sudah begitu mapan ini. Meskipun dapat kita terima bahwa lembaga paling penting dalam proses pendidikan adalah rumah tangga dan tempat kerja.

Usulan Toffler (1992:354-358) jauh lebih rasional dan realistis. Menurut beliau, sistem persekolahan di masa depan harus direformasi (bukan dihapuskan). Sasaran utama pendidikan masa depan adalah meningkatkan "kemampuan menanggulangi" (cope ability) individu. Tiap komunitas dan sekolah harus membentuk dewan masa depan yang bertugas untuk mengkaji dan menjajaki segala kemungkinan yang akan terjadi di masa depan, selanjutnya memproyeksikan suatu asumsi masa depan dengan mendefenisikan tanggapan pendidikan yang koheren dengan asumsi itu. Perlu dibangun beberapa alternatif citra masa depan yang sinambung, yaitu asumsi tentang jenis pekerjaan, profesi dan kejuruan yang mungkin diperlukan 20 atau 50 
tahun ke depan; berbagai asumsi mengenai bentuk keluarga dan hubungan antar manusia yang akan berlaku, masalah etik dan moral yang akan timbul, teknologi yang akan mengelilingi kita dan struktur organisasi yang akan kita masuki. Selanjutnya, Toffler menyarankan agar sistem persekolah jangan terlalu kaku. Seorang anak bisa saja tidak perlu mengikuti beberapa mata pelajaran sekolah, jika saja pelajaran tersebut dapat diketahui melalui sumber lain, misalnya, orang tuanya kebetulan seorang ilmuwan yang mampu dan berkesempatan mengajar anak tersebut. Dalam hal ini sang anak hanya menjalin kontrak belajar untuk mata pelajaran tertentu. Di samping itu, tempat belajar bukan hanya di kelas tetapi lebih banyak di luar kelas, bukan untuk mengamati tetapi terjun langsung dalam kehidupan riel masyarakat. Tegasnya, sekolah masa depan, menurut versi Toffler, bukanlah sekawanan gedung, murid-murid yang berseragam, bel keluar-masuk, daftar mata pelajaran, guru otoriter, rapor, jumlah sks, IPK, gelar, ijazah dan sebagainya dan seterusnya.

\section{SEKOLAH MASA LALU}

Dari mana sebenarnya asal usul sekolah? Dan apa yang dimaksud dengan sekolah pada saat pertama kali kemunculannya?

Sekolah, dalam bahasa aslinya (Latin) skhole, scola, scolae atau schola, secara harfiah berarti "waktu luang" atau "waktu senggang" atau "waktu luang yang digunakan khusus untuk belajar". Konon, orang Yunani waktu dulu biasanya mengisi waktu luang mereka dengan cara mengunjungi suatu tempat atau seseorang pandai tertentu untuk mempertanyakan dan mempelajari hal ihwal yang mereka rasakan memang perlu mereka ketahui. Kegiatan ini mereka sebut skhole, scola, scolae atau schola. Pengetahuan yang mereka peroleh tersebut mereka ajarkan pula pada putra-putri mereka. Dan setelah desakan perkembangan kehidupan kian menyita waktu orang tua, mereka pun tak sempat lagi mengajar putra putri mereka. Akhirnya, waktu luang anak-anak diisi dengan cara menitipkan mereka pada orang-orang tempat orang tuanya dulu ber-schola. Sejak saat itulah sebagian fungsi scola matterna (pengasuhan ibu hingga masa tertentu) menjadi scola in loco parentis (lembaga pengasuhan anak pada waktu 
senggang, sebagai pengganti ayah ibu). Lembaga pengasuhan ini biasa disebut "ibu asuh" atau "ibu yang memberikan ilmu" (almamater) (Topatimasang, 1998:5-11).

Bila saja istilah sekolah dipahami seperti makna asli kata itu, maka kita tidak perlu menghabiskan separuh dari umur kita hanya untuk bersekolah. Di samping itu, kita bebas untuk mengetahui apa yang ingin kita ketahui dan apa yang memang butuh kita ketahui. Bukan sebaliknya, kita dipaksa untuk mempelajari hal-hal yang sama sekali tidak ingin kita ketahui, dan terkadang malah membuat kita tak sempat mempelajari apa sebenarnya yang ingin kita ketahui. Seperti kata Reimer, bahwa yang paling buruk yang dapat dikatakan tentang sekolah ialah bahwa ia merampas waktu secara besar-besaran. Waktu belajar seseorang secara bebas terancam dua bahaya: pertama, sekolah menyita waktu orang itu, kedua, sekolah menghabiskan dana yang sebenarnya bisa memperkaya dirinya (Reimer, 2000:103).

Barangkali kita perlu menghidupkan kembali schole masa lalu, tentu saja dengan sedikit inovasi tanpa mengurangi orisinalitasnya, sebagai salah satu media alternatif bagi pendidikan masyarakat. Mungkin hal ini jauh lebih muda ketimbang mengikuti saran Illich yang menghendaki penghapusan sekolah, atau pun solusi Toffler yang membutuhkan reformasi sistem persekolahan yang tak mungkin terjadi tanpa perubahan sistem dan kultur sosial.

Azra (2000:109-116), menawarkan salah satu bentuk lembaga pendidikan alternatif yang beliau istilahkan dengan "Universitas Rakyat". Karakteristik lembaga ini tercermin dalam proses pendidikannya yang berlangsung seumur hidup dan menyeluruh, melibatkan seluruh potensi rakyat sehingga menjadi educational society. Universitas Rakyat jauh dari bentuk kelembagaan yang penuh birokratis dan hubungan formalistik, akrab dengan masyarakat, setiap individu bisa jadi guru sesuai dengan ilmu dan keahliannya masingmasing berdasarkan tanggung jawab sosial, tidak ada batas usia, kurikulum, materi dan model pembelajaran tidak terikat sesuai dengan kebutuhan masyarakat, intinya pelajaran atau keahlian dapat dikuasai. Di universitas ini tidak dikenal sistem ujian, apalagi embel-embel ijazah dan gelar, setiap individu mengevaluasi dirinya sendiri. Lembaga ini menjadi suatu pusat studi yang mempelajari dan mengikuti gerak sosial. Karena itu, ia dapat pula menjadi pusat 
pengembangan teknologi, riset ilmiah, bengkel kerja, pusat kebudayaan, sanggar seni, laboratorium eksperimen, pengajian agama dan sebagainya. Dana universitas ini ditanggung bersama, baik melalui iuran, wakaf, infak, sadaqah dan lain-lain.

Gagasan tentang Universitas Rakyat ini tampaknya lebih dekat pada pengertian sekolah yang sesungguhnya seperti yang pernah dipraktekkan oleh orang-orang Yunani dulu. Hanya saja ada sejumlah pengembangan yang disesuaikan dengan konteks sosial masyarakat modern.

\section{PENUTUP}

Memberdayakan sekolah sebagai lembaga pendidikan formal, tidak cukup dengan hanya merubah sistem kelembagaannya, tetapi yang terpenting adalah merubah paradigma masyarakat tentang sekolah. Sekolah merupakan ciptaan masyarakat. Oleh karena itu, ia akan tampil menurut apa yang dicitrakan masyarakat terhadapnya, ia akan hadir sesuai dengan apa yang dikehendaki oleh masyarakat. Ketika dalam masyarakat terjadi dominasi kelas tertentu terhadap yang lain, termasuk dalam hal ini mendominasi pengambilan keputusan dalam hal persekolahan, maka segeralah sekolah akan menjadi instrumen penindasan. Semakin banyak sekolah semakin dalam jurang pemisah antara kelas atas dengan kelas bawah, semakin banyak rakyat miskin yang tertindas. Sekolah tidak lagi menjadi lembaga pemberdayan masyarakat, tetapi berubah menjadi lembaga yang memperdaya masyarakat.

\section{DAFTAR PUSTAKA}

Azra, Azyumardi. 2000. Esai-esai Intelektual Muslim dan Pendidikan Islam. Jakarta: Logos Wacana Ilmu

Collins, Randall. 1974. "Where are Educational Requirements for Employment Highest?", dalam Sosiologi of Education 47

Dewey, John. 1962a. Child and Curriculum. Chicago: The University of Chicago Press.

Dewey, John. 1962b. The School and Society. Chicago: The University of Chicago Press.

Eskobar, M., et. al. 1998. Sekolah Kapitalisme yang Licik: Dialog Bareng Paulo Freire Terjemahan oleh Muhdi Rahayu. Yogyakarta: LkiS. 
Freire, Paulo. T. Th. Pendidikan Kaum Tertindas. Terjemahan oleh Utomo Dananjaya et.al., 1985. Jakarta: LP3ES.

Husen, Torsten. 1988. Masyarakat Belajar. Terjemahan oleh P. Surono Hargosenoyo dan Yusuf Hadi Miarso Cet. I. Jakarta: Rajawali.

Hutchins, Robert Maynard. 1968. "Are We Educating Our Children for the Wrong Future?" dalam Frank H. Blackington III dan Robert S. Patterson (Ed.), School, Society and the Professional Educator. New York: Holt, Rinehart and Winston, Inc.

Illich, Ivan. 1972. Deschooling Society. New York: Harper \& Row Publisher.

Reimer, Everett. T. Th. Matinya Sekolah. Terjemahan oleh Joko Suryatno. 2000. Yogyakarta: Hanindita Graha Widia.

Toffler, Alvin. Kejutana Masa Depan. Cet. IV. Terjemahan oleh Sri Koesdiyatinah SB, 1992. Jakarta: Pantja Simpati.

Topatimasang, Roem. 1998. Sekolah itu Candu. Yogyakarta: Pustaka Pelajar. 